\title{
The Newfoundland and Labrador Bariatric Surgery Cohort Study: Rational and Study Protocol
}

Laurie K. Twells ${ }^{1,2 *}$, Deborah M. Gregory ${ }^{2,3}$, William K. Midodzi ${ }^{2}$, Carla Dillon ${ }^{1}$, Christopher S. Kovacs ${ }^{2}$, Don MacDonald ${ }^{4}$, Kendra K. Lester ${ }^{2}$, David Pace ${ }^{2,3}$, Chris Smith ${ }^{2,3}$, Darrell Boone ${ }^{2,3}$ and Raleen Murphy ${ }^{3}$

\begin{abstract}
Background: In Canada, there has been a disproportionate increase in adults with Class II (BMI 35.0-39.9 kg/ $\mathrm{m}^{2}$ ) or Class III obesity (BMI $\geq 40 \mathrm{~kg} / \mathrm{m}^{2}$ ) affecting $9 \%$ of Canadians with increases projected. Individuals affected by severe obesity $(\mathrm{BMI} \geq 35)$ are at increased risk of high blood pressure, cardiovascular disease, diabetes, cancer, impaired quality of life, and premature mortality. Bariatric surgery is the most effective treatment for severe obesity. Laparoscopic sleeve gastrectomy (LSG), a relatively new type of bariatric surgery, is growing in popularity as a treatment. The global prevalence of LSG increased from 0 to $37.0 \%$ between 2003 and 2013. In Canada and the US, between 2011 and 2013, the number of LSG surgeries increased by $244 \%$ and LSG now comprises $43 \%$ of all bariatric surgeries. Since 2011, Eastern Health, the largest regional health authority in Newfoundland and Labrador (NL), Canada has performed approximately 100 LSG surgeries annually.
\end{abstract}

Methods: A population-based prospective cohort study with pre and post surgical assessments at 1, 3, 6, 12, 18, 24 months and annually thereafter of patients undergoing LSG. This study will report on short - to mid-term ( $2-4$ years) outcomes. Patients ( $n=200$ ) followed by the Provincial Bariatric Surgery Program between 19 and 70 years of age, with a BMI between 35.0 and $39.9 \mathrm{~kg} / \mathrm{m}^{2}$ and an obesity-related comorbidity or with a BMI $\geq 40 \mathrm{~kg} / \mathrm{m}^{2}$ are enrolled. The study is assessing the following outcomes: 1) complications of surgery including impact on nutritional status 2) weight loss/regain 3) improvement/resolution of comorbid conditions and a reduction in prescribed medications 4) patient reported outcomes using validated quality of life tools, and 5) impact of surgery on health services use and costs. We hypothesize a low complication rate, a marked reduction in weight, improvement/resolution of comorbid conditions, a reduction in related medications, improvement in quality of life, and a decrease in direct healthcare use and costs and indirect costs compared to pre-surgery.

Discussion: Limited data on the impact of LSG as a stand-alone procedure on a number of outcomes exist. The findings from this study will help to inform evidence-based practice, clinical decision-making, and the development of health policy.

Keywords: Obesity, Bariatric surgery, Laparoscopic sleeve gastrectomy, Health outcomes, Canada

\footnotetext{
*Correspondence: Itwells@mun.ca

'School of Pharmacy, Memorial University, Health Sciences Centre, 300 Prince

Philip Drive, St. John's, NL A1B 3 V6, Canada

${ }^{2}$ Faculty of Medicine, Memorial University, Health Sciences Centre, 300 Prince

Philip Drive, St. John's, NL A1B 3 V6, Canada

Full list of author information is available at the end of the article
} 


\section{Background}

Obesity, most often defined using body mass index or BMI $\left(\mathrm{kg} / \mathrm{m}^{2}\right)$, is classified in categories that are reflective of the increasing health risk associated with excess body weight (Class I: BMI 30.0-34.9 kg/m², Class II BMI $35.0-39.9 \mathrm{~kg} / \mathrm{m}^{2}$, Class III $\mathrm{BMI} \geq 40.0 \mathrm{~kg} / \mathrm{m}^{2}$ ) [1, 2]. Severe obesity, herein defined as Class II and III, is associated with much higher levels of morbidity, increased demands on the health care system, and premature death [3-5]. It increases the risks of developing high blood pressure, cardiovascular disease and type 2 diabetes [3], significantly impairs quality of life [6], and shortens life expectancy [5].

Over the last three decades, the prevalence of obesity has increased in many countries [7]. In Canada, obesity currently affects $25 \%$ of adults with severe obesity increasing over $400 \%$ since 1985 and now affecting nearly $10 \%$ of the population or approximately 1,000,000 Canadians $[8,9]$. The estimated annual economic burden of obesity evidenced by direct costs related to hospitalizations, medication use, physician and emergency room visits, and indirect costs related to reduced work productivity and increased absenteeism, is now estimated to be between $\$ 4.6$ billion and $\$ 7.1$ billion $[10,11]$.

\section{Bariatric surgery}

Severe obesity is difficult to treat. Treatments that include changes in diet, exercise, behavioral modification/ counselling, medical management or pharmacotherapy have demonstrated limited effectiveness as successful treatments for weight loss or long-term weight control. On average these interventions result in a modest weight loss of $5-10 \%$ of initial body weight [12-14].

Bariatric surgery, the most effective treatment for those with severe obesity, offers significant and sustained weight loss, improvement in comorbid conditions and quality of life, and reduces the risk of death [15-23]. Canadian guidelines exist on the surgical treatment of adult obesity. Surgery is indicated in medically refractory patients with a BMI $\geq 35 \mathrm{~kg} / \mathrm{m}^{2}$ plus obesity-related comorbidity condition (e.g., hypertension, diabetes) or a $\mathrm{BMI} \geq 40 \mathrm{~kg} / \mathrm{m}^{2}[3]$.

There are several different types of bariatric surgery and all involve an alteration of the digestive system in either a restrictive, malabsorptive, or combination restrictive/malabsorptive capacity [3, 20-23]. Restrictive type bariatric procedures impose a physical limitation on the amount of food that can be consumed by reducing gastric volume. The most common procedures include (a) laparoscopic sleeve gastrectomy (LSG) where the greater curvature and fundus of the stomach are surgically resected leaving an elongated tube or stomach 'sleeve' and (b) adjustable gastric banding (AGB) where the proximal stomach is encircled with an adjustable band that is progressively inflated to create a small restrictive gastric pouch. Malabsorptive procedures restrict nutrient and calorie absorption in the small intestine and include the biliopancreatic diversion/duodenal switch (BPD/DS). Other bariatric surgeries use a combination of restriction and malabsorption to promote weight reduction, and of these the most commonly performed is the gold standard roux-en-y gastric bypass (RYGB) which results in a highly restrictive gastric pouch coupled with a diversion of the upper small intestine [21].

In 2003, 146,301 bariatric procedures were performed worldwide with the majority $(103,000)$ performed in the United States and Canada. The types of procedures comprised of $85 \%$ RYGB, $9 \%$ AGB, and $4.5 \%$ BPD/DS [24]. Since 2003, a significant shift has occurred in the type of procedure being performed. In 2013, the total number of worldwide procedures increased to 468,609 (with 154,276 performed in US/Canada) and was comprised of $45.0 \%$ RYGB, 37.0 \% LSG, 10.0 \% AGB, and 1.5 \% BPD/DS. Similar to the worldwide shift in type of procedure being performed, in Canada and the US, between 2011 and 2013, the number of LSG surgeries increased by $244 \%$ and now comprises $43 \%$ of all bariatric surgeries [25].

These changes reflect the exponential growth of LSG both worldwide and in the United States and Canada [25]. Over $90 \%$ of bariatric surgeries are performed laparoscopically [21]. This minimally invasive approach reduces surgical risk, hospital stay, and recovery time compared to open techniques and has contributed to the increasing popularity of this approach [26].

\section{Bariatric surgery outcomes}

A recently published systematic review and meta-analysis by Chang et al. [27] on the effectiveness and risks of bariatric surgery provides an update on studies published between 2003 and 2012 comparing surgical and nonsurgical treatments for severe obesity. This review includes 164 studies $(n=161,756)$ : 37 randomized controlled trials (RCT) and 127 observational studies (OBS). Just over half of the studies, $54 \%(n=91)$, provided follow-up data on patients for $\geq 2$ years. The mean age (years) and BMI $\left(\mathrm{kg} / \mathrm{m}^{2}\right)$ of patients was 44.6 and 45.6, respectively and almost $80 \%$ were women. Average presurgery weight was $124.53 \mathrm{~kg}$. About a quarter of the patients had diabetes (26\%), dyslipidemia (27\%) and sleep apnea (25\%), while almost half had hypertension (47\%). The review reported on the three most common bariatric procedures currently performed by type of study, RCT or OBS. Average percent excess weight loss (\%EWL) at 3 years was $57 \%$ (RCTs) and $67 \%$ (OBS). Remission of comorbid conditions occurred in the majority of patients: diabetes $92 \%$ (RCT), $86 \%$ (OBS); hypertension $75 \%$ (RCT), 74\% (OBS); dyslipidemia 76 \% (RCT), 68 \% (OBS); 
sleep apnea 96 \% (RCT), $90 \%$ (OBS). Complication rates were $17 \%$ (95\% CI 11-23 \%) (RCT) and $10 \%$ (95\% CI $7-13 \%)(\mathrm{OBS})$ and reoperation rates were $7 \%$ (95 \% CI 3-12\%) (RCT) and $6 \%$ (95\% CI 4-8 \%) (OBS). In the RCT group the 30-day mortality rate was $0.08 \%$ (95\% CI 0.01-0.24) compared to $0.31 \%$ (95 \% CI $0.01-0.75 \%$ ) for the OBS group.

\section{Mortality}

Compared to non-surgical treatments for obesity, bariatric surgery is associated with a reduced risk of death $[16,18,28-30]$. A recent meta-analysis reported that bariatric surgery reduced the risk of mortality and cardiovascular mortality when compared to non-surgical interventions through a reduction in myocardial infarction, diabetes, and cancer-related deaths [28]. A reduced risk of mortality within $2-5$ years of surgery has been reported in Canadian (89 \%) [18], Australian (72 \%) [30] and US (40\%) studies [29]. The Swedish Obesity Study (SOS) of more than 2000 patients, age and sex matched with obese controls, reported a $29 \%$ reduction in mortality (adjusted HR $0.7195 \%$ CI 0.54-0.92) at 16 years [16]. More recent data from the SOS on 20 year mortality outcomes report an even more significant reduction (HR $0.4795 \%$ CI 0.29-0.76) in cardiovascular death (including MI and stroke) [31].

\section{Quality of life}

Health related quality of life (HRQoL) encompasses measures of well-being and physical and psychosocial functioning [32]. Severe obesity is associated with significantly impaired HRQoL [32, 33]. In general, HRQoL improves in patients after bariatric surgery [19, 34-36]. However, findings are inconsistent [37], and improvements may often be limited to physical functioning with less improvement observed in emotional or mental functioning [36]. In addition very limited data on the long-term ( $>5$ years) impact of bariatric surgery on quality of life exists [38].

\section{Complications}

Data on complications suggest the benefits of bariatric surgery outweigh the harms $[26,27]$. Perioperative mortality is low $(<0.3 \%)$ and declining [38]. The incidence of complications (e.g., pulmonary complications, vomiting, wound infection, hemorrhage, anastomotic leak) in the first 30-180 days after surgery varies widely from 4 to $25 \%$ and depends on the definition of complication used, type of procedure, duration of follow-up, and individual patient characteristics. A study by Hutter et al. [39] reviewed the complication rates of 22,365 cases (944 LSG, 14,491 LRYGB, 988 open RYGB, 12,193 LAGB) and found that LSG fell below LRYGB but above LAGB for postoperative rates of morbidity, mortality, readmission, and reoperation rates. Long-term, the rates of reoperation as a result of complications, insufficient weight loss, or weight regain are a concern [40]. The effect of LSG on acid reflux is still controversial and requires further research [41]. Longer term there is some evidence that nutritional deficiencies (e.g., calcium, vitamin D, iron, zinc) may develop after bariatric surgery and the effect on bone health is unknown and also requires further study [26].

Emerging data from observational studies suggest that some bariatric procedures may increase the risk of substance misuse disorders (i.e., alcohol) and suicide [42]. Pharmacokinetic studies suggest that changes in the gastrointestinal anatomy after gastric bypass and sleeve gastrectomy may lead to a more rapid absorption of alcohol and increases in blood alcohol concentrations per dose, inadvertently increasing the frequency of physiological binges and subsequent alcohol misuse disorder [42, 43]. The risk of suicide after bariatric surgery may be increased but the cause is unclear [42]. The Utah Mortality study among others has demonstrated a small but significant increase in the number of suicides after surgery [29]. In addition, there are anecdotal reports of the development of addictive behaviors such as gambling, shoplifting, and driven sexual behavior [43]. It should be noted that these observations are limited due to the paucity of data on long-term psychological assessment in these patients.

\section{Economic evaluation}

Studies have reported that bariatric surgery, mainly RYGB and AGB, are more cost-effective than nonsurgical care [21, 22, 44-46] due to sustained weight reduction, decreased use of medications (especially for diabetes and cardiovascular disease), reduced outpatient and physician visits, and improved quality of life. However, the complexity of RYGB is associated with early complications resulting in increased inpatient stays. As well, the overall costs of AGB are increased due to reoperations and band removals [47]. Newer procedures, such as LSG have the potential to yield increased cost savings due to its relatively low complication rate and early evidence that clinical outcomes such as weight loss and comorbid resolution are comparable with RYGB [48]. There has not been an economic evaluation of LSG.

\section{Laparoscopic sleeve gastrectomy as a treatment for severe obesity}

LSG began as the first stage of a two-tiered operation of duodenal switch or RYGB for very large (e.g., BMI $\geq$ $50 \mathrm{~kg} / \mathrm{m}^{2}$ ) or high-risk patients [3, 22, 49, 50]. Sleeve gastrectomy involves the surgical resection of the greater curvature and fundus of the stomach which creates an elongated tube or stomach 'sleeve' along the lesser 
curvature. This sleeve has a volume of $60-100 \mathrm{ml}$, effectively restricting caloric intake and increasing feelings of satiety. Removal of the fundus has also been associated with endocrine and metabolic effects [21], for example, the reduction of circulating levels of ghrelin - a hunger hormone, which may reduce the desire for food. It is not yet fully understood how LSG creates favorable metabolic changes and weight loss but this topic is a major focus of research. Since the early 2000's, LSG grew in popularity as a stand-alone bariatric surgery because of the perceived technical ease of performing the surgery, associated obesity-related comorbidity improvement or resolution, and good short-term weight loss outcomes $[25,26]$. It is now recognized as a primary bariatric surgery option and as a first-stage procedure in high-risk patients as part of a planned staged approach [26]. In a recent systematic review conducted by Victorzon in 2012, the author noted that the quantity, quality, and consistency of evidence for LSG for the treatment of obesity were low. Victorzon suggested that although numerous short-term studies had shown that LSG had good outcomes of between 45-60\% EWL, no longer term studies with $>100$ patients have been published [50]. For LSG, average clinically expected \%EWL has been reported to be $56.1 \%$ within the first year after surgery but there is limited data on sustained or continued weight loss longer term [51]. In a systematic review [51] the maximum weight loss reportedly occurred at 24 and 36 months following LSG surgery with \%EWL's of $64.3 \%(46.1-75.0 \%)$ and $66.0 \%(60.0-77.5 \%)$, respectively [51]. In a small study examining average \%EWL 5 years following surgery \%EWL was $86 \%$ (50-103\%), but only 49 patients had complete follow-up data [52].

In general, bariatric surgery is effective in the resolution of many obesity-related medical comorbidities (e.g., type 2 diabetes mellitus [T2DM], hypertension, sleep apnea) [53], although data comparing the impact of RYGB and LSG on T2DM is inconsistent. A recent systematic review and meta-analysis compared the gold standard RYGB to LSG and found no significant difference in resolution of T2DM at 3 years (81 vs. $80 \%$ ) [54], however, other studies have shown inconsistent results when comparing the two procedures on improvements in glycemic control, achieving glycated hemoglobin value, and remission $[49,55,56]$. In contrast to T2DM, there does not appear to be a significant difference between RYGB and LSG on other comorbid conditions including dyslipidemia and hypertension $[55,57]$. However, the development of reflux disease after LSG has been reported $[57,58]$ but a recent systematic review evaluating the effect of LSG on GERD reported inconsistent outcomes [59].

\section{Knowledge gaps}

The prevalence of severe obesity has increased dramatically in Canada and bariatric surgery is currently the only effective treatment option offered to medical refractory patients. Identifying cost-effective strategies to treat severe obesity must be a priority for governments and healthcare systems as healthcare expenditures of severely obese adults are double that of normal weight individuals [60]. Since 2003, there has been an exponential increase in the number of LSG's performed as a treatment for severe obesity. There is evidence to support the efficacy of LSG in terms of weight loss and comorbid improvement/resolution, however data on other outcomes are limited (e.g., weight loss sustainability or recidivism, comorbid regression, nutritional deficiencies, non-alcoholic fatty liver disease [NAFLD], polycystic ovary syndrome [PCOS], quality of life, health services use and costs, short-term psychiatric problems), especially when based on a sample size of at least $80 \%$ with follow-up of 2 years and beyond. In a review of bariatric literature by Puzziferri et al., to identify studies that had $80 \%$ or greater follow-up at 2 years and beyond, $<3 \%$ of studies (29/1136) met this inclusion criterion. Not all studies reported adequate weight loss data or outcome data on diabetes, hypertension, and dyslipidemia [61]. The authors state that the estimates of the treatment effect are very likely biased (overestimated) due to missing weight loss and other outcome data on representative samples. It is suggested that bariatric studies use more rigorous methods of patient engagement and retention in order to mitigate loss to follow-up [61].

\section{The Newfoundland and Labrador Bariatric Surgery Cohort (BaSCo) study}

Study objective The objective of the current study is to examine short- to mid-term outcomes (2-4 years) associated with LSG. Eligible patients who have undergone LSG will be followed during and after surgery to assess health and other outcomes. Specific study objectives are to examine:

1. 30-day complication rate and mortality, and long-term complications (e.g., gastroesophageal reflux, micronutrient deficiencies).

2. reduction in weight and/or body mass index (BMI), including predictors of successful weight loss.

3. improvement or resolution of co-morbid conditions (i.e. diabetes, hypertension, dyslipidemia, NAFLD, PCOS).

4. changes in prescription and over-the-counter medication use.

5. improvement in measures of health-related quality of life and

6. the economic consequences associated with LSG (e.g., direct costs and indirect costs). 
In the short- to mid-term we hypothesize a low rate of complications, a marked reduction in weight, improvement/resolution of comorbid conditions, a reduction in obesity-related medications, an improvement in quality of life, and a decrease in direct healthcare and indirect costs compared to pre-surgery costs.

\section{Methods/Design}

\section{Study design}

This is a prospective cohort study examining the effectiveness of LSG on patient health outcomes.

\section{Study population Setting}

The Provincial Bariatric Surgery Clinic is located in Eastern Health $(\mathrm{EH})$. EH is the largest of four regional integrated health authorities in Newfoundland and Labrador (NL) and provides a full continuum of health services to a regional population of more than 300,000 . It is also responsible for a number of unique provincial programs, for example, the Provincial Bariatric Surgery Clinic. The Provincial Bariatric Surgery Clinic was established in May 2011. This multidisciplinary team consists of three surgeons trained in bariatric surgery, a nurse practitioner, and other allied health professionals. Potential patients are most often referred via their primary care provider to the clinic and are invited to attend a pre-surgical education session. After the session, interested patients meet with the bariatric nurse practitioner where a detailed medical history is taken. Patients then meet with a bariatric surgeon, and if deemed to be a surgical candidate, they sign consent to undergo bariatric surgery, specifically LSG. At the time the team was developed, LSG was the only bariatric procedure offered to eligible patients in the province.

\section{Patient selection criteria for bariatric surgery}

The eligible population consists of all patients who (1) meet the Canadian Practice Guidelines criteria for the surgical treatment of obesity (BMI $\geq 35$ with risk factors, or $\mathrm{BMI} \geq 40$ ) [3], (2) are referred by their primary care provider to the bariatric team using a standardized referral form submitted to a central intake system, and (3) receive preliminary eligibility screening by the nurse practitioner. Following mandatory attendance at a presurgical bariatric surgery general orientation and an education session provided either face-to-face or via webinar, patients are required to undergo an extensive pre-operative work-up which includes a 2-week diet trial (i.e., 1 week full-fluid diet and 1 week healthy eating) as well as a food journaling activity. All patients meet one-on-one or via Telehealth with the nurse practitioner for further assessment including a detailed review of their weight history and past weight loss attempts, blood work and a sleep study to identify and treat any sleep disordered breathing, as necessary. If any other medical concerns are identified, patients are consulted to the appropriate specialist (e.g., cardiologist, endocrinologist, respirologist) based on their comorbid condition. An appointment with one of the three bariatric surgeons in the bariatric surgery clinic is arranged to obtain formal surgical consent.

\section{Inclusion criteria}

- Male or female patients between 19 and 70 years of age

- $\mathrm{BMI} \geq 40 \mathrm{~kg} / \mathrm{m}^{2}$ or $\geq 35 \mathrm{~kg} / \mathrm{m}^{2}$ with significant obesity-related comorbidities

- Maximum BMI $60 \mathrm{~kg} / \mathrm{m}^{2}$ as per NL Bariatric Surgery Program guidelines

- Attempted nonsurgical weight loss in the past

- Deemed medically, psychologically, and emotionally stable to consent to surgery and partake in a diet and lifestyle modification regime

\section{Exclusion criteria}

\section{- Pregnant}

\section{Recruitment for bariatric surgery study}

Once deemed eligible for surgery, a research nurse coordinator approaches every patient to discuss potential interest in the study. The research nurse gives each eligible participant a brief explanation of the study, an introductory letter addressed from the researcher, an information sheet, and consent form, and asks if she can contact them to discuss the research project in greater detail after the potential participant has had 24 to $48 \mathrm{~h}$ to review the materials. If agreeable to this request, the research nurse calls or makes contact with the potential participant at the bariatric surgery clinic or by telephone to answer any questions and set-up a time during the next visit to the clinic to obtain written consent and complete baseline data collection. The study protocol is illustrated in Fig. 1.

\section{Surgical intervention}

The surgical intervention is performed laparoscopically under general anesthesia. A 6 port technique is performed. The vascular supply of the stomach is divided along the greater curve, starting $5 \mathrm{~cm}$ proximal to the pylorus and up to the angel of His. A gastric sleeve is created using multiple applications of a $60 \mathrm{~mm}$ linear stapler after the sleeve size is calibrated using a $42 \mathrm{Fr}$ bougie. The gastric specimen is removed via the left upper quadrant port site. An endoscopic air leak test is routinely done to confirm an intact staple line, and an 


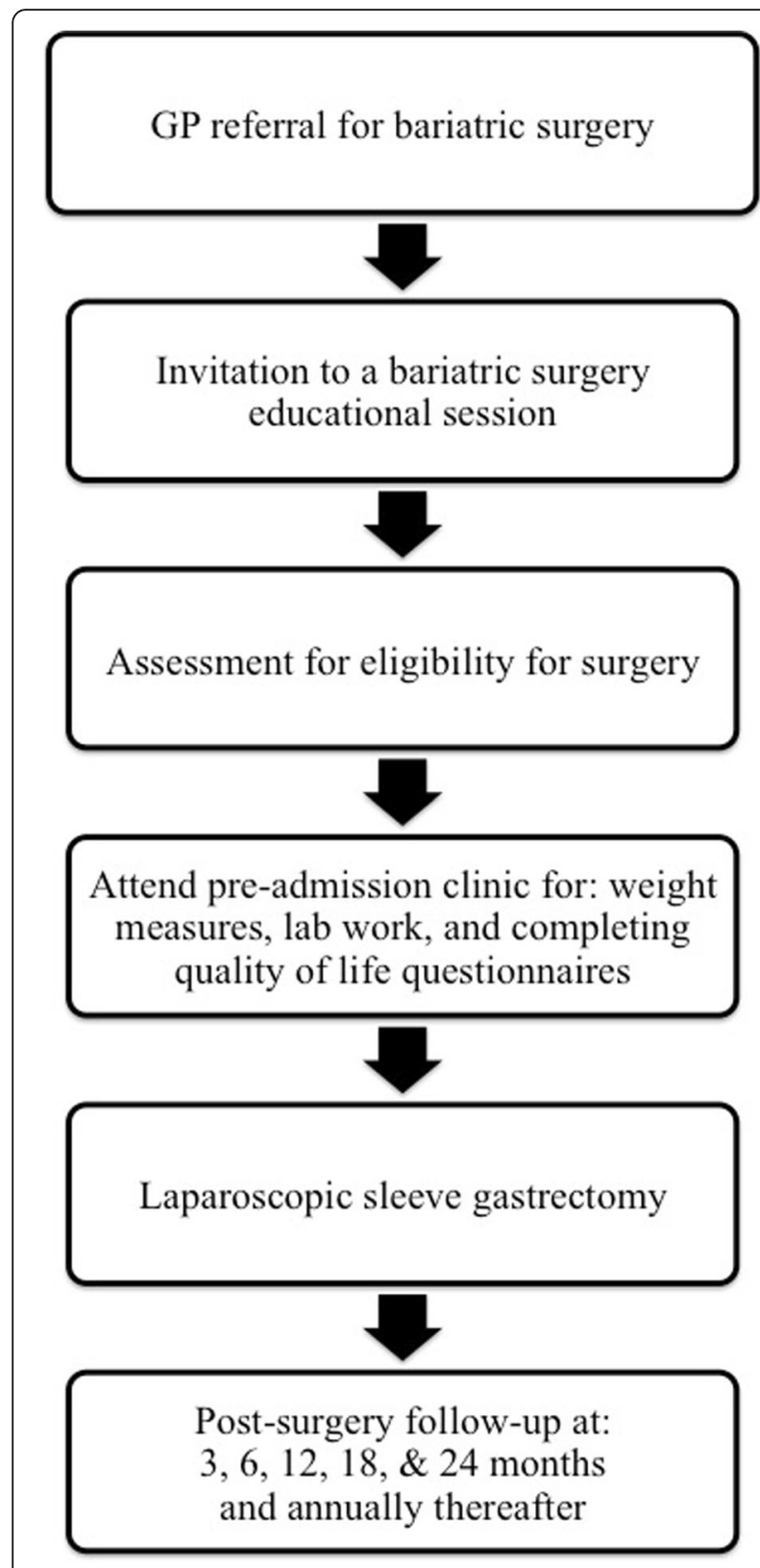

Fig. 1 The NL Bariatric Surgery Cohort Study: Patient Flow

upper gastrointestinal contrast study is performed on the first postoperative day before the introduction of oral liquid diet. If this is clear, patients are started on a clear liquid diet and are normally discharged home on postoperative day two with dietary instructions.

\section{Data collection}

Patients are followed by the provincial bariatric surgery clinic team as standard of care. The patients are assessed by a bariatric surgeon $6-8$ weeks post-surgery. In-person follow-up visits or assessments via Tele-health with the
Nurse Practitioner/bariatric care team take place at 1, 3, $6,12,18$, and 24 months, and annually thereafter.

\section{Study measures}

Standardized case report forms (SCRFs) developed in collaboration with Eastern Health and in consultation with other Canadian bariatric programs are used to collect relevant research and clinical data. Clinical data such as weight measures and blood work are collected by the clinical team (the nurse practitioner) and provided to the research team via a research nurse. The research nurse collects data on individual patients at each follow-up visit using the SCRFs (Table 1).

\section{Evaluation of health care utilization and costs}

The impact of bariatric surgery on the health system will be examined by comparing health care use and costs (e.g., physician visits, hospitalizations, medications and associated costs) 3 years pre-and 2 years post-surgery (Table 2). In NL, the Centre for Health Information (NLCHI) maintains a number of key health-related data sources on behalf of the provincial Ministry of Health. These databases comprehensively capture patientspecific health care resource utilization. These include vital statistics (mortality) and validated, high quality, detailed measurement of the following health care resources and costs: inpatient and outpatient encounters, physician billings, diagnostic tests, procedures, and long-term care use. In addition to providing detailed information allowing patient-specific costing of each encounter, inpatient databases record diagnostic and procedural information using the ICD-10-CA and CCI classification systems [62]. Using unique provincial health insurance numbers, the NLCHI will link the bariatric clinical/research data with administrative health services data and provide the research team with a deidentified database of health services use and costs for data analysis purposes $[63,64]$.

\section{Outcomes}

\section{Primary outcome: weight loss}

Absolute (kg, BMI) changes and percent changes (\%EWL, \%TWL, \% change in BMI) from baseline will be reported. Percent Excess Weight Loss (\%EWL) is calculated as100\% $\mathrm{x}([\mathrm{W0}-\mathrm{W} 1] / \mathrm{EW} 0)$ where W0 is the weight $(\mathrm{kg})$ at the time of the surgery, W1 is the weight $(\mathrm{kg})$ at the last follow-up and EW0 is the excess weight at the time of the surgery, based on ideal weights found in the Metropolitan tables for middle frame individuals [65]. Percent Total Weight Loss (\%TWL) is calculated as $100 \% \mathrm{x}([\mathrm{W} 0-\mathrm{W} 1] / \mathrm{W} 0)$ where W0 is the weight $(\mathrm{kg})$ at the time of the surgery, W1 is the weight $(\mathrm{kg})$ at the last follow-up. Using definitions of successful weight loss 12 months after bariatric surgery, we will calculate the 
Table 1 Study measures and data collection time periods

\begin{tabular}{|c|c|c|c|}
\hline Study Measures & Source & Variable & Time frame $(\mathrm{s})$ \\
\hline Socio-demographics/Lifestyle & $\begin{array}{l}\text { Patient } \\
\text { Interview }\end{array}$ & $\begin{array}{l}\text { Age, sex, ethnicity, current marital status, highest level } \\
\text { of education, occupation, current employment status, } \\
\text { current household income level, smoking status } \\
\text { (current, past, never) }\end{array}$ & Pre-surgery \\
\hline Anthropometric & $\begin{array}{l}\text { Standardized } \\
\text { Case Report } \\
\text { Form }\end{array}$ & Weight ${ }^{1}$, height ${ }^{2}$, BMI $^{3}$ & $\begin{array}{l}\text { Pre-surgery, } 3,6,12,18, \\
24 \text { months and annually } \\
\text { thereafter }\end{array}$ \\
\hline $\begin{array}{l}\text { Medical History/Self-reported } \\
\text { baseline comorbid conditions }\end{array}$ & $\begin{array}{l}\text { Standardized } \\
\text { Case Report } \\
\text { Form }\end{array}$ & $\begin{array}{l}\text { Diabetes, hypertension, dyslipidemia, } \\
\text { sleep apnea, NAFLD, PCOS, etc. }\end{array}$ & Pre-surgery \\
\hline $\begin{array}{l}\text { Assessment of obesity-related } \\
\text { comorbid conditions to evaluate } \\
\text { changes in comorbid status }\end{array}$ & $\begin{array}{l}\text { Standardized } \\
\text { Case Report Form } \\
\text { Patient Interview }\end{array}$ & Diabetes, hypertension, dyslipidemia, NAFLD, PCOS & $\begin{array}{l}3,6,12,18,24 \text { months } \\
\text { and annually thereafter } \\
\text { PCOS will be assessed } \\
\text { at } 12 \text { months only }\end{array}$ \\
\hline Medication use & $\begin{array}{l}\text { Standardized } \\
\text { Case Report Form }\end{array}$ & $\begin{array}{l}\text { Prescribed and over-the-counter medications } \\
\text { (name, type, dosage, frequency and duration) }\end{array}$ & $\begin{array}{l}\text { Pre-surgery, } 3,6,12,18, \\
24 \text { months and annually } \\
\text { thereafter }\end{array}$ \\
\hline Clinical characteristics & $\begin{array}{l}\text { Standardized } \\
\text { Case Report Form }\end{array}$ & Blood pressure ${ }^{4}$, heart rate & $\begin{array}{l}\text { Pre-surgery, 3, 6, 12, 18, } \\
24 \text { months and annually } \\
\text { thereafter }\end{array}$ \\
\hline Laboratory values & $\begin{array}{l}\text { Meditech } \\
\text { laboratory } \\
\text { module }\end{array}$ & $\begin{array}{l}\text { HbA1c, fasting blood glucose, insulin level, creatinine, fasting } \\
\text { lipid panel (including total cholesterol, LDL, HDL, triglycerides), } \\
\text { high sensitivity (hs) CRP, GGT, albumin, total bilirubin, ALP, } \\
\text { ALT, total protein, ferritin, hemoglobin, MCV, TSH, 25-OH D, } \\
\text { Vitamin B12 }\end{array}$ & $\begin{array}{l}\text { Pre-surgery, } 3,6,12,18, \\
24 \text { months and annually } \\
\text { thereafter }\end{array}$ \\
\hline Health-related QoL & Validated surveys & SF 12v2, EQ-5D, IWQoL-Lite & $\begin{array}{l}\text { Pre-surgery, } 6,12,18, \\
24 \text { months }\end{array}$ \\
\hline Operative data & $\begin{array}{l}\text { Clinical database and } \\
\text { chart review }\end{array}$ & Minor and major complications & $\begin{array}{l}\text { During surgery and up to } \\
30 \text { days post-surgery }\end{array}$ \\
\hline
\end{tabular}

proportion of patients who attain ( $>50 \%$ EWL). In addition, the proportion of subjects that achieve clinically important weight loss (i.e. $\geq 5$ and $10 \%$ ) will be reported [3].

\section{Sample size calculation}

The primary outcome for the sample size determination was defined as successful weight loss at 12 months after bariatric surgery. This was calculated as percentage of patients who attain ( $>50 \% \mathrm{EWL})$ at 12 months postsurgery. Sample size was estimated using an online calculator for population surveys as follows: $n=\left(Z^{2} \times P\right.$ $(1-P)) / E^{2}$ where $\mathrm{Z}=$ value from standard normal distribution corresponding to desired confidence level $(\mathrm{Z}=1.28$ for $80 \% \mathrm{CI}$ ), $\mathrm{P}$ is expected true proportion and $\mathrm{E}$ is desired precision (half desired CI width). Assuming that 50-60\% of patients undergoing LSG will achieve the primary outcome of weight loss (>50\% EWL), a total of 165 patients will be required for a precision of $\pm 5 \%$ at a confidence level of $80 \%$. To account for missing information from some patients, the sample size has been inflated to 200 .

\section{Secondary outcomes}

1. Complications of surgery 30-day complication rate and mortality will be reported. Longer-term complications such as gastroesophageal reflux and micronutrient deficiencies will be examined. To examine micronutrient deficiencies, the following biochemical parameters associated with micronutrients will be assessed (25-hydroxyvitamin D (25-OH-D), parathyroid hormone (PTH), calcium, vitamin B12, ferritin, mean cell volume (MCV) and hemoglobin). The analysis for 25-OH-D used liquid chromatography coupled with tandem mass spectrometry. Hemoglobin and MCV were analyzed on the Beckman Coulter HMX Hematology Analyzer, while ferritin, vitamin B12, and intact PTH 
Table 2 Short to mid-term health care use and costs in surgical patients

\begin{tabular}{|c|c|c|c|c|}
\hline Cost Category & Units of Resources & $\begin{array}{l}\text { Newfoundland \& Labrador } \\
\text { Source Details }\end{array}$ & $\begin{array}{l}\text { Newfoundland \& Labrador } \\
\text { Costing Source }\end{array}$ & Time Frame \\
\hline 1. Inpatient encounters & $\begin{array}{l}\text { \# of hospitalizations (acute care) } \\
\text { Length-of-stay (LOS) }\end{array}$ & $\begin{array}{l}\text { Newfoundland and Labrador Centre } \\
\text { for Health Information (NLCHI) Clinical } \\
\text { Database Management System (CDMS), } \\
\text { based on the Discharge Abstract Database } \\
\text { (DAD) includes LOS, procedures performed, } \\
\text { associated diagnoses, RIW and complexity } \\
\text { values }\end{array}$ & $\begin{array}{l}\text { NLCHI/Canadian Institute for Health } \\
\text { Information (CIHI) methodology to } \\
\text { cost acute care encounters using } \\
\text { resource-intensity-weights (RIW) } \\
\text { and complexity values }\end{array}$ & $\begin{array}{l}\text { Provided by fiscal year. } \\
\text { Referenced to time zero } \\
\text { (date of surgery) }\end{array}$ \\
\hline 2. Outpatient encounters & $\begin{array}{l}\text { \# encounters } \\
\text { \# procedures }\end{array}$ & $\begin{array}{l}\mathrm{NLCHI} \text { CDMS (based on DAD) includes } \\
\text { surgical day care procedures }\end{array}$ & $\begin{array}{l}\mathrm{NLCHI} / \mathrm{CIHI} \text { methodology to cost } \\
\text { surgical day care encounters }\end{array}$ & $\begin{array}{l}\text { Provided by fiscal year. } \\
\text { Referenced to time zero }\end{array}$ \\
\hline 3. Physician Fees (Fee for Service) & $\begin{array}{l}\text { \# of encounters } \\
\text { Provider specialty } \\
\text { Service provided }\end{array}$ & Medical Care Plan (MCP) Physician Claims & MCP Physician Claims & $\begin{array}{l}\text { Provided by fiscal year. } \\
\text { Referenced to time zero }\end{array}$ \\
\hline 4. Physician Fees (self-report) & $\begin{array}{l}\text { \# of encounters } \\
\text { Provider specialty } \\
\text { Service provided }\end{array}$ & $\begin{array}{l}\text { Patient interview (standardized case } \\
\text { report form) }\end{array}$ & Estimated using MCP Physician Claims & $\begin{array}{l}\text { Information obtained every } \\
6 \text { months }\end{array}$ \\
\hline 5. Medications & Name dosage, frequency \& duration & $\begin{array}{l}\text { Patient interview (standardized case } \\
\text { report form) }\end{array}$ & NL Drug (Provincial Formulary) & $\begin{array}{l}\text { Information obtained every } \\
6 \text { months }\end{array}$ \\
\hline 6. Transfer Payments & $\begin{array}{l}\text { Unemployment insurance } \\
\text { Disability benefits }\end{array}$ & $\begin{array}{l}\text { Patient interview (standardized case } \\
\text { report form) }\end{array}$ & Patient Reported & $\begin{array}{l}\text { Information obtained every } \\
6 \text { months }\end{array}$ \\
\hline 8. Employment status, absenteeism & $\begin{array}{l}\text { Employment status in past year } \\
\text { (\# hours/week, \# weeks) } \\
\text { Absenteeism in past year (\# days) } \\
\text { Annual income (by quintile) }\end{array}$ & $\begin{array}{l}\text { Patient interview (standardized } \\
\text { case report form) }\end{array}$ & $\begin{array}{l}\text { Average wage rate by age, sex and } \\
\text { region from Statistics Canada }\end{array}$ & $\begin{array}{l}\text { Information obtained every } \\
6 \text { months }\end{array}$ \\
\hline 9. Weight Loss Interventions & $\begin{array}{l}\text { Weight loss program, meal replacements, } \\
\text { physical trainer, exercise programs, } \\
\text { alternative therapies (Binary } \mathrm{Y} / \mathrm{N} \text { ) }\end{array}$ & $\begin{array}{l}\text { Patient interview (standardized } \\
\text { case report form) }\end{array}$ & $\begin{array}{l}\text { Patient reported out of pocket cost } \\
\text { Costs lists of rehabilitation supplies } \\
\text { \& equipment }\end{array}$ & $\begin{array}{l}\text { Information obtained every } \\
6 \text { months }\end{array}$ \\
\hline 10. Mobility and Medical & $\begin{array}{l}\text { Mobility aids, home modification/renovations, } \\
\text { rehabilitation, paid personal assistance } \\
\text { (household activities and home productivity, } \\
\text { driving) } \\
\text { (Binary } \mathrm{Y} / \mathrm{N} \text { ) }\end{array}$ & $\begin{array}{l}\text { Patient interview (standardized } \\
\text { case report form) }\end{array}$ & $\begin{array}{l}\text { Patient reported out of pocket } \\
\text { cost/co-payments for medical services } \\
\text { Costs lists of rehabilitation supplies } \\
\text { \& equipment }\end{array}$ & $\begin{array}{l}\text { Information obtained every } \\
6 \text { months }\end{array}$ \\
\hline
\end{tabular}

DAD Discharge Abstract Database, LOS Length of stay, CIHI Canadian Institute for Health Information, CDMS Clinical Database Management System, RIW Resource Intensity Weight, MCP Newfoundland and Labrador

Medical Care Plan, EH Eastern Health 
were analyzed on the Architect i System by Abbots Diagnostics. Calcium was analyzed on the Architect c System by Abbots Diagnostics.

2. Comorbid Condition Improvement/Resolution Improvement in comorbid conditions (i.e. hypertension and dyslipidemia) is defined as any reduction in medication use or treatment. Comorbidity resolution is defined as complete cessation of treatment/medication.

For the comorbid conditions of prediabetes and type 2 diabetes mellitus, specific definitions of diagnosis are used as outlined in the Canadian Diabetes Association Clinical Practice Guidelines [66]. Prediabetes is defined as fasting plasma glucose (FPG) levels of $6.1-6.9 \mathrm{mmol} / \mathrm{L}$ and/or glycated hemoglobin (A1C) levels of 6.0-6.4 \% [66]. Type 2 diabetes mellitus is defined as $\mathrm{FPG} \geq 7.0 \mathrm{mmol} / \mathrm{L}$ and/or $\mathrm{A} 1 \mathrm{C} \geq 6.5 \%$ [66].

Additional criteria will used to assess improvement and resolution of prediabetes and diabetes [67]. Case definitions of improvement and remission of prediabetes will be as follows: Improvement will be based on achievement of the following: (1) lower glycemic measures (2) at least 1 year's duration, and (3) pharmacologic therapy required but at a lower dose. Normalization is defined as (1) normal glycemic measures (2) at least 1 year's duration, and (3) pharmacologic therapy required but at a lower dose. Remission is based on (1) normal glycemic measures (2) at least 1 year's duration, and (3) no active pharmacologic therapy. Case definitions of improvement and remission of Type 2 diabetes mellitus [67] will be defined as follows.

Improvement will be based (1) hyperglycemia below diagnostic thresholds for T2DM (2) at least 1 year's duration, and (3) pharmacologic therapy required but at a lower dose. Partial remission is based on the following (1) hyperglycemia below diagnostic thresholds for T2DM (2) at least 1 year's duration, and (3) no active pharmacologic therapy. Complete remission is based on the following criteria (1) normal glycemic measures (2) at least 1 year's duration, and (3) no active pharmacologic therapy. The status of specific biochemical parameters associated with NAFLD prior to and following LSG will be assessed using the following markers: total bilirubin, alanine phosphatase (ALP), alanine transaminase (ALT), gamma glutamyl transpeptidase (GGT), high-density lipoprotein (HDL), low-density lipoprotein (LDL), and triglycerides. Biochemical parameters associated with NAFLD were analyzed on the Architect c System by Abbots Diagnostics. The prevalence of PCOS will be determined prior to surgery based on self-report while changes in related (e.g., period frequency and regularity, menstrual flow and intensity, hirsutism, acne, fertility, post-surgery conception) and metabolic symptoms (insulin sensitivity, T2DM, dyslipidemia, hypertension) will be examined 1-year after LSG.

3. Change in medication use

Changes in prescription and over-the-counter medication use and associated costs will be examined including total number of medications and changes (dose changes, medication discontinuations, and initiation of additional medications) by disease indication.

4. Quality of Life

Health related quality of life is assessed using validated instruments. Generic and disease-specific instruments will be used. All participants will complete the Short Form (SF)-12, Euroqol (EQ)-5D, and the Impact of Weight on Quality of Life (IWQOL)-Lite pre-surgery at $6,12,18$, and 24 months after surgery. The SF-12 (Version 2) is a condensed 12-question version of the SF-36 [68]. It yields a physical and a mental health component summary score. Three-to-five point difference in either score are considered clinically meaningful $[69,70]$. The EQ-5D is an indirect preference-based health survey that consists of a 5 dimension descriptive system [71] and an overall health visual analog scale (EQ- VAS). A 0.03 point difference in EQ-5D index score and 10 point difference on the EQ-VAS are considered clinically meaningful [72]. The IWQOL-Lite is a short form of the IWQOL and is the first instrument specifically developed to assess the effects of obesity on the quality of life of persons who are seeking weight loss treatment [73]. The IWQOL-lite consists of 31 items that describe 5 domains of obesity-specific HRQL. A difference in the total score of 7-12 points for IWQOL-Lite is considered clinically meaningful [74].

5. Economic consequences of bariatric surgery Direct healthcare use/costs (e.g., hospitalizations, physician visits, medication use) and indirect costs (e.g., cost of weight loss interventions, employment and absenteeism, home productivity, transfer payments) will be compared 3 years prior to surgery and 2 years post- surgery in order to determine the economic consequences of bariatric surgery.

\section{Data analysis}

Non-identifying patient information obtained from the standardized case report forms used to collect patient information at baseline, administrative records and medical chart reviews were entered into a Statistical Package for Social Sciences database. All statistical analyses will be performed using IBM SPSS Statistics for Windows, 
version 20.0 [75]. Descriptive analysis will include demographic details of patients pre-surgery and clinical information collected at the time of surgery. In each analysis to be conducted to address the six main research objectives for this program, categorical variables (such as 30-day complication rate and mortality; and long-term complications e.g., gastro esophageal reflux, micronutrient deficiencies) will be presented as frequencies and chi-square tests conducted to identify differences in pre-post surgical outcomes. Continuous variables with a normal distribution will be reported as means \pm SD. Variables with a non-normal distribution will be reported as medians and interquartile ranges. For example, health services use such as number of physician visits often has a non-normal distribution; therefore median and quartiles will be reported when comparing use pre- and post-surgery. The Analysis of Variance (ANOVA) or the paired $t$-method will be used to assess differences in continuous outcome pre and post-surgery. Pairwise-comparison of pre with post-surgical patients' outcomes at 3, 6, 12, 18 and 24 months will be done using matched t-tests for continuous outcomes such as BMI. Regression analyses methods will be performed to identify independent predictors of outcomes of interest (i.e., reduction in weight and/or BMI, including predictors of successful weight loss; improvement or resolution of co-morbid conditions (i.e., diabetes, hypertension, dyslipidemia, NAFLD, PCOS); changes in prescription and over-the-counter medication use; improvement in measures of health-related quality of life. For continues outcomes, mean differences, standard errors, $95 \%$ confidence intervals and p-values will be presented. For categorical outcomes, odds ratios and $95 \%$ confidence intervals will be presented. Generalized estimating equations with binary logistic regression will be used for all response or outcome events to take into account the correlations between repeated measures postsurgery providing an estimated adjusted odds ratio and $95 \%$ confidence intervals. Statistical significance is set at $p<0.05$.

To examine the predictors of change in patient's 2 years post-surgery, MIXED modelling regression approach [76, 77] implemented in SPSS will be used to assess baseline patient's factors that determine individual changes in individual maintaining weight loss over the 24 months. The mixed modeling approach will also allow us to take into account the correlations between repeated measures and accounts for missing data over time. Statistical significance effect of factors producing changes or reduction in weight and/or BMI, including predictors of successful weight loss overtime in the 24 month post-surgery would be set at $p<0.05$. Costeffectiveness will be performed to evaluate the economic consequences associated with LSG. The economic analyses will be carried out on a per protocol basis and would be based on patients for whom there was complete resource use and health outcome data provided by the NL Centre for Health Information.

\section{Ethics and privacy}

We have received full ethics approval for the NL Bariatric Surgery Study [Health Research Ethics Authority (HREA) 11.101]. Patient informed consent was obtained and subjects were informed they could withdraw from the study at any time. The research nurse is the only member of the team who has access to identifying patient information. This information is kept in a locked cabinet in a secure office. De-identified data is secured in password protected files and only accessed by researchers involved in the study for the purpose of data analysis. As with previous projects involving the compilation of sensitive datasets from multiple sources such as cancer registries and physician billings, the protection of individual privacy and anonymity and confidentiality will be maintained by having NLCHI act as a trusted third party.

\section{Discussion}

In summary, the demand for LSG as a stand-alone procedure is growing in popularity as a treatment for class II and III obesity. In a joint report "Developing a Research Agenda to Support Bariatric Care" published by the CIHR and the Canadian Obesity Network in 2010, the gaps in research related to bariatric surgery were highlighted [78]. Although LSG was not specifically highlighted in the report, compared to other bariatric surgeries, research on LSG as a treatment for severe obesity is limited due to its relatively recent provision as a stand-alone procedure. The start-up of a bariatric surgery program offering LSG as a treatment for severe obesity combined with the limited research on LSG provided an opportunity for research. Consequently, an Integrated Knowledge Translation Team was established at Memorial University, comprised of academic researchers, healthcare professionals, decision-makers, and policy makers, and a program of research on bariatric care was developed to address key gaps in the research literature. One of the studies designed and implemented within this program of research and presented in this paper is a quasiexperimental study that aims to address current knowledge gaps in LSG by generating prospective, population-based Canadian outcome data. This study is being conducted in a provincial bariatric surgery program within a tertiary care teaching centre and the results will be generalizable to similar programs offering bariatric surgery. A current review continues to highlight a major concern previously identified by others $[79,80]$ associated with bariatric surgery as a treatment for obesity. It is not the magnitude of 
initial weight loss which has been well documented but the mid- to long-term sustainability of weight loss that is under question. Very few bariatric studies report long-term results with sufficient patient follow-up ( $>80 \%)$ in order to minimize biased results. In addition, insufficient evidence exists regarding long-term outcomes for LSG [61]. In response to this concern and as part of the current study protocol, a clinical database to house all program data in order to monitor longer-term ( $>5$ years) patient health outcomes has been developed which will also allow for data linkages with administrative data to examine health care use and costs in the future. Further interventions being used in order to decrease attrition and increase patient engagement include the use of technology (e.g., Tele-health and webinar sessions for educational purposes). As of August 2015, $100 \%$ recruitment has been achieved with completion of follow-up to be completed by September 2016 with study results to be published in late 2016 and early 2017. Our study population is $82 \%$ female, with an average age, weight, and BMI of 44 years, $135 \mathrm{kgs}$ and $49 \mathrm{~kg} / \mathrm{m}^{2}$, respectively. The prevalence rates of hypertension and dyslipidemia were approximately 50 and $43 \%$ had T2DM. Our study participants are similar to other patient populations that are eligible for and undergoing bariatric surgery elsewhere in Canada $[15,21]$, increasing the external validity of our study findings.

\section{Abbreviations}

25-OH-D: 25 Hydroxy Vitamin D; A1C: Glycated hemoglobin; AGB: Adjustable gastric banding; ALP: Alkaline phosphatase; ALT: Alanine transaminase; ANOVA: Analysis of variance; BMI: Body mass index; BPD/DS: Biliopancreatic diversion/duodenal switch; EQ-5D: Eurogol 5D; EWL: Excess weight loss; FPG: Fasting plasma glucose; GGT: Gamma-glutamyl transferase; HDL: High-density lipoprotein; HREA: Health Research Ethics Authority; HRQOL: Health related quality of life; IWQoL: Impact of weight on quality of life; LAGB: Laparoscopic adjustable gastric banding; LDL: Low-density lipoprotein; LSG: Laparoscopic sleeve gastrectomy; MCV: Mean cell volume; NAFLD: Nonalcoholic fatty liver disease; NL: Newfoundland and Labrador; NLCHI: Newfoundland and Labrador Centre for Health Information; OBS: Observational study; PCOS: Polycystic ovarian syndrome; PTH: Parathyroid hormone; RCT: Randomized controlled trial; RYGB: Roux-en-y gastric bypass; SCRFs: Standardized case report forms; SD: Standard deviation; SF-12: Short form 12; SF-36: Short form 36; T2DM: Type 2 diabetes mellitus; VAS: Visual analogue scale

\section{Acknowledgements}

We would like to acknowledge Kim Manning, the research nurse for this study, who recruited patients and collected follow-up data. Most importantly we would like to acknowledge all the patients who consented to take part in this very important research study.

\section{Funding}

The research study protocol is funded by the Newfoundland and Labrador Centre for Applied Health Research. We received in-kind funding from Eastern Health and the NL Centre for Health Information.

\section{Availability of data and material}

The datasets analysed during the current study are available from the corresponding author on reasonable request.

\section{Authors' contributions}

LT and DG are co-principal investigators of the NL Bariatric Surgery Cohort Study and drafted the initial study concept and research protocol. LT, DG,
WM, CD, CK, DM, KL, DP, CS, DB and RM contributed to the study design and funding application. WM and $\mathrm{KL}$ are responsible for data management and statistical analysis. All authors read, provided input and approved the final manuscript.

\section{Competing interests}

The authors declare that they have no competing interests.

\section{Consent for publication}

NA

Ethics approval and consent to participate

We received full ethics approval for the NL Bariatric Surgery Cohort Study from the Newfoundland and Labrador Provincial Health Research Ethics Authority (HREA) \#11.101. Patient informed consent was obtained and subjects were informed they could withdraw from the study at any time.

\section{Author details}

${ }^{1}$ School of Pharmacy, Memorial University, Health Sciences Centre, 300 Prince Philip Drive, St. John's, NL A1B 3 V6, Canada. ${ }^{2}$ Faculty of Medicine, Memorial University, Health Sciences Centre, 300 Prince Philip Drive, St. John's, NL A1B 3 V6, Canada. ${ }^{3}$ Eastern Health, Health Sciences Centre, 300 Prince Philip Drive, St. John's, NL A1B 3 V6, Canada. ${ }^{4}$ Research and Evaluation, Newfoundland and Labrador Centre for Health Information, 70 O'Leary Avenue, St. John's, NL A1B 2C7, Canada.

Received: 5 August 2016 Accepted: 20 October 2016

Published online: 28 October 2016

\section{References}

1. WHO Consultation on Obesity. Obesity: preventing and managing the global epidemic. Report of a WHO consultation. World Health Organ Tech Rep Ser. 2000;894:i-xii. 1-253.

2. Canadian guidelines for body weight classifications in adults. Ottawa: Health Canada; 2003. Cat no H49-179/2003E.

3. Lau DC, Douketis JD, Morrison KM, et al. 2006 Canadian clinical practice guidelines on the management and prevention of obesity in adults and children [summary]. CMAJ. 2007;176 Suppl 8:S1-S13.

4. Twells LK, Bridger T, Knight JC, et al. Obesity predicts primary health care visits: a cohort study. Popul Health Manag. 2012;15(1):29-36.

5. Flegal KM, Kit BK, Orpana H, Graubard BI. Association of all-cause mortality with overweight and obesity using standardized body mass index categories. A systematic review and meta-analysis. JAMA. 2013;309(1):71-82.

6. Sarwer DB, Lavery M, Spitzer JC. A review of the relationships between extreme obesity, quality of life and sexual function. Obes Surg. 2012;22(4):668-76.

7. Sassi F, Devaux M. OECD obesity update 2012. [www.oecd.org/health/ 49716427.pdfl. Accessed 17 Feb 2014

8. Jansen I. The public health burden of obesity in Canada. Can J Diabetes. 2013;37(2):90-6.

9. Twells L, Gregory DM, Reddigan J, Midodzi W. Current prevalence and future predictions of obesity in Canada: A trend analysis. CMAJ Open. 2014; 2(1):E18-26.

10. Anis AH, Zhang W, Bansback N, et al. Obesity and overweight in Canada: an updated cost-of-illness study. Obes Rev. 2010;11(1):31-40.

11. Obesity in Canada. Ottawa (ON). A joint report from the Public Health Agency of Canada \& Canadian Institute for Health Information; 2011. Cat no HP5-107?2011E-PDF.

12. Moyer VA. US Preventive Servcies Task Force: Screening for and management of obesity in adults: US Preventive Servcies Task Force recommendation statement. Ann Intern Med. 2012;157(5):376-8.

13. Avenell A, Broom J, Brown TJ, et al. Systematic review of the long term effects and economic consequences of treatments for obesity and implications for health improvement. Health Technol Assess. 2004;8(21):iii-iv. 1-182.

14. LeBlanc E, O'Connor E, Whitlock EP, Patnode C, Capka T. Screening for and management of obesity and overweight in adults. Rockville (MD): Agency for Healthcare Research and Quality (US) 2011, Report No. 11-05159-EF-1

15. Padwal RS, Rueda-Clausen CF, Sharma AM, Aqhorsangaya CB, et al. Weight loss and outcomes in wait-listed, medically managed and surgically treated patients enrolled in a population-based bariatric program: prospective cohort study. Med Care. 2014;52(3):208-15. 
16. Sjöström L, Nabro K, Sjöström CD, et al. Effects of bariatric surgery on mortality in Swedish obese subjects. N Engl J Med. 2007;357(8):741-52.

17. Chang $\mathrm{SH}$, Stoll CR, Colditz GA. Cost-effectiveness of bariatric surgery: should it be universally available? Maturitas. 2011;69(3):230-8.

18. Christou NV, Sampalis JS, Liberman M, et al. Surgery decreases long-term mortality, morbidity, and health care use in morbidly obese patients. Ann Surg. 2004;240(3):416-23. discussion 423-424.

19. Karlsson J, Taft C, Rydén A, et al. Ten-year trends in health-related quality of life after surgical and conventional treatment for severe obesity: the SOS intervention study. Int J Obes (Lond). 2007;31(8):1248-61.

20. Belle SH, Berk PD, Courcoulas AP, Flum DR, Miles CW, Mitchell JE, et al. Safety and efficacy of bariatric surgery: Longitudinal assessment of bariatric surgery. Surg Obes Relat Dis. 2007;3(2):116-26.

21. Padwal R, Klarenbach S, Wiebe N, Hazel M, Birch D, Karmali S, et al. Bariatric surgery: a systematic review of the clinical and economic evidence. J Gen Intern Med. 2011;26(10):1183-94.

22. Picot J, Jones J, Colquitt JL, Gospodarevskaya E, Loveman E, Baxter L, et al. The clinical effectiveness and cost-effectiveness of bariatric (weight loss) surgery for obesity: a systematic review and economic evaluation. Health Technol Assess. 2009;13(41):1-190. 215-357, iii-iv.

23. Stefater MA, Wilson-Pérez HE, Chambers AP, Sandoval DA, Seeley RJ. All bariatric surgeries are not created equal: insights from mechanistic comparisons. Endocr Rev. 2012;33(4):595-622.

24. Buchwald H, Oien DM. Metabolic/bariatric surgery worldwide 2008. Obes Surg. 2009;19(12):1605-11.

25. Angrisani L, Santonicola A, lovino P, Formisano G, Buchwald H, Scopinaro N. Bariatric surgery worldwide 2013. Obes Surg. 2015;25(10):1822-32

26. Mechanick Jl, Youdium A, Jones DB, et al. Clinical practice guidelines for the perioperative nutritional, metabolic, and nonsurgical support of the bariatric surgery patient-2013 update: cosponsored by American Association of Clinical Endocrinologists, the Obesity Society, and American Society for Metabolic \& Bariatric Surgery. Endocr Pract. 2013;19(2):337-72

27. Chang SH, Stoll CR, Song J, Varela JE, et al. The effectiveness and risks of bariatric surgery: An updated systematic review and meta-analysis, 2003-2012. JAMA Surg. 2014;149(3):275-87.

28. Pontiroli AE, Morabito A. Long-term prevention of mortality in morbid obesity through bariatric surgery. A systematic review and meta-analysis of trials performed with gastric banding and gastric bypass. Ann Surg. 2011;253(3):484-7.

29. Adams TD, Gress RE, Smith SC, et al. Long-term mortality after gastric bypass surgery. N Engl J Med. 2007;357(8):753-61.

30. Peeters A, O'Brien PE, Laurie C, et al. Substantial intentional weight loss and mortality in the severely obese. Ann Surg. 2007;246(6):1028-33.

31. Sjöström L, Peltonen $M$, Jacobson $P$, et al. Bariatric surgery and long-term cardiovascular events. JAMA. 2012;307(1):56-65.

32. van Nunen AM, Wouters EJ, Vingerhoets AJ, Hox JJ, Geenen R. The Health-related quality of life of obese persons seeking or not seeking surgical or non-surgical treatment: a meta-analysis. Obes Surg. 2007;17(10):1357-66.

33. Kolotkin RL, Crosby RD, Williams GR. Health-related quality of life varies among obese subgroups. Obes Res. 2002;10(8):748-56.

34. Herpetz S, Kielmann R, Wolf AM, Langkafel M, et al. Does obesity surgery improve psychosocial functioning? A systematic review. Int J Obes Relat Metab Disord. 2003;27(11):1300-14.

35. Kolotkin RL, Crosby RD, Gress RE, Hunt SC, Adams TD. Two-year changes in health-related quality of life in gastric bypass patients compared with severely obese controls. Surg Obes Relat Dis. 2009:5(2):250-6.

36. Kolotkin RL, Davidson LE, Crosby RD, Hunt SC, Adams TD. Six-year changes in health-related quality of life in gastric bypass patients versus obese comparison groups. Surg Obes Relat Dis. 2012;8(5):625-33.

37. van Hout GC, Boekestein P, Fortuin FA, et al. Psychosocial functioning following bariatric surgery. Obes Surg. 2006;16(6):787-94.

38. Arterburn DE, Courcoulas AP. Briatric surgery for obesity and metabolic conditions in adults. BMJ. 2014;349:g3961. doi:10.1136/bmj.g3961.

39. Hutter MM, Schirmer BD, Jones BD, Ko CY, Cohen ME, Merkow RP, Nguyen NT. First Report from the American College of Surgeons Bariatric Surgery Center Network. Ann Surg. 2011;254(3):410-22

40. Pech $\mathrm{N}$, Meyer $\mathrm{F}$, Lippert $\mathrm{H}$, et al. Complications and nutrient deficiencies two years after sleeve gastrectomy. BMC Surgery 2012, 12(13): doi:10.1186/1471-2482-12-13

41. Sarkhosh K, Birch DW, Sharma A, Karmali S. Complications associated with laparoscopic sleeve gastrectomy for morbid obesity: a surgeon's guide. Can J Surg. 2013;56(5):347-52.
42. Marcus MD, Kalarchian MA, Courcoulas AP. Psychiatric evaluation and follow-up of bariatric surgery patients. Am J Psychiatry. 2009;166(3):285-91.

43. Sogg S. Alcohol misuse after bariatric surgery: epiphenomenon or "Oprah" phenomenon. Surg Obes Relat Dis. 2007;3(3):366-8.

44. Jensen C, Flum DR. The costs of nonsurgical and surgical weight loss interventions: Is an ounce of prevention really worth a pound of cure? Surg Obes Relat Dis. 2005;1(3):353-7.

45. Salem L, Jensen CC, Flum DR. Are bariatric surgical outcomes worth their cost? A systematic review. J Am Coll Surg. 2005;200(2):270-8.

46. Salem L, Devlin A, Sullivan SD, Flum DR. Cost-effectiveness analysis of laparoscopic gastric bypass, adjustable gastric banding and nonoperative weight loss interventions. Surg Obes Relat Dis. 2008;4(1):26-32.

47. Weiner JP, Goodwin SM, Chang HY, et al. Impact of bariatric surgery on health care costs of obese persons: A 6-year follow-up of surgical and comparison cohorts using health plan data. JAMA Surg. 2013;148(6):555-62.

48. Schauer PR, Kashyap SR, Wolski K, et al. Bariatric surgery versus intensive medical therapy in obese patients with diabetes. N Engl J Med. 2012; 366(17):1567-76

49. Breathauer SA. Sleeve gastrectomy. Surg Clin North Am. 2011:91(6):1265-79.

50. Victorzon M. An update on sleeve gastrectomy. Minerva Chir. 2012;67(2): 153-63.

51. Fischer $L$, Hildebrandt $C$, Bruckner T. Excessive weight loss after sleeve gastrectomy: A systematic review. Obes Surg. 2012;22(5):721-31.

52. Rawlins L, Rawlins MP, Bown CC, Schumacher DL. Sleeve gastrectomy: 5-year outcomes of a single institution. Surg Obes Relat Dis. 2013;9(1):21-5.

53. Buchwald $H$, Estok R, Fahrback $K$, et al. Weight and type 2 diabetes after bariatric surgery: systematic review and meta-analysis. Am J Med. 2009; 122(3):248-56. e5.

54. Yip S, Plank LD, Murphy R. Gastric bypass and sleeve gastrectomy for type 2 diabetes: a systematic review and meta-analysis of outcomes. Obes Surg. 2013;23(12):1994-2003.

55. Schauer PR, Bhatt DL, Kirwan JP, et al. Bariatric surgery versus intensive medical therapy for diabetes: 3-year outcomes. N Engl J Med. 2014;370(21): 2002-13.

56. Jiménez A, Casamitjana R, Flores L, et al. Long-term effects of sleeve gastrectomy and Roux-en-Y gastric bypass surgery on type 2 diabetes mellitus in morbidly obese subjects. Ann Surg. 2012;256(6):1023-9.

57. Zhang N, Maffei A, Cerabona T, et al. Reduction in obesity-related comorbidities: Is gastric bypass better than sleeve gastrectomy? Surg Endosc. 2013;27(4):1273-80.

58. Howard DD, Caban AM, Cendan JC, Ben-David K. Gastroesophogeal reflux after sleeve gastrectomy in morbidly obese patients. Surg Obes Relat Dis. 2011;7(6):709-13.

59. Chiu S, Birch DW, Shi X, et al. Effect of sleeve gastrectomy on gastroesophageal reflux disease: A systematic review. Surg Obes Relat Dis. 2011;7(4):510-5.

60. Finkelstein EA, DiBonaventura MD, Burgess SM, Hale BC. The costs of obesity in the workplace. J Occup Environ Med. 2010;52(10):971-6.

61. Puzziferri N, Roshek 3rd TB, Mayo HG, et al. Long-term follow-up after bariatric surgery: a systematic review. JAMA. 2014;312(9):934-42.

62. Canadian Institute for Health Information. Canadian coding standards for ICD-10-CA and CCI. [https://secure.cihi.ca/estore/productSeries. htm?locale=en\&pc=PCC189]. Accessed 29 July 2014.

63. Twells L, Knight J, Alaghebandan R, et al. Obesity and its impact on a provincial health system in Canada: a cost analysis. Ann Epidemiol. 2007; 17(9):739.

64. Twells LK, Bridger $T$, Knight JC, et al. Obesity predicts primary health care visits: a cohort study. Popul Health Manag. 2011. doi:10.1089/pop. 2010.0081.

65. Deitel M, Greenstein RJ. Recommendations for reporting weight loss. Obes Surg. 2003;13(2):159-60.

66. Goldenberg R, Punthakee X. Definition, classification and diagnosis of diabetes, prediabetes and metabolic syndrome. Can J Diabetes. 2013;37 suppl 1:S1-S212.

67. Buse JB, Caprio S, Cefalu WT, et al. How do we define cure of diabetes? Diabetes Care. 2009:11(32):2133-5.

68. SF-36.org: The SF-12(r): An even shorter health survey. [http://www.sf36.org/ tools/sf12.shtml]. Accessed 29 July 2014

69. Stewart AL, Greenfield S, Hays RD, et al. Functional status and well-being of patients with chronic conditions: Results from the medical outcomes study. JAMA. 1989;262(7):907-13. 
70. Weyrwich K, Tierney W, Babu A, et al. A Comparison of Clinically Important Differences in Health-Related Quality of Life for Patients with Chronic Lung Disease, Asthma, or Heart Disease. Health Serv Res. 2005;40(2):577-91.

71. EurolQol Research Foundation. EQ-5D is a standardized instrument for use as a measure of health outcomes. [http://www.euroqol.org/about-eq-5d.html]. Accessed 29 July 2014.

72. Luo N, Johnson J, Coons SJ. Using instrument-defined health state transitions to estimate minimally important differences for four preference-based healthrelated quality of life instruments. Med Care. 2010;48(4):365-71.

73. Kolotkin RL. Quality of Life Consulting: Impact of Weight on Quality of Life-Lite (IWQOL-Lite). [http://www.qualityoflife consulting.com/iwqol-lite.html]. Accessed 29 July 2014.

74. Crosby RD, Kolotkin RL, Williams GR. Defining clinically meaningful change in health-related quality of life. J Clin Epidemiol. 2003;56(5):395-407.

75. IBM Corp. released 2011. IBM SPSS Statistics for Windows, Version 20.0. Armonk, NY: IBM Corp.

76. Twisk JWR. Applied longitudinal data analysis for epidemiology. A practical guide. UK: Cambridge University Press; 2003.

77. Singer JD, Willett JB. Applied longitudinal data analysis. Modeling change and event occurrence. UK: Cambridge University Press; 2003.

78. Developing a research agenda to support bariatric care in Canada workshop report. Montreal (QC). Canadian Institutes of Health Research \& Canadian Obesity Network; 2010. Cat no MR21/2011E-PDF.

79. American Society for Metabolic and Bariatric Surgery. Updated position statement on sleeve gastrectomy as a bariatric procedure. Surg Obes Relat Dis. 2010;6(1):1-5.

80. Shi X, Karmali S, Sharma AM, Birch DW. A review of laparoscopic sleeve gastrectomy for morbid obesity. Obes Surg. 2010;20(8):1171-7.

\section{Submit your next manuscript to BioMed Central and we will help you at every step:}

- We accept pre-submission inquiries

- Our selector tool helps you to find the most relevant journal

- We provide round the clock customer support

- Convenient online submission

- Thorough peer review

- Inclusion in PubMed and all major indexing services

- Maximum visibility for your research

Submit your manuscript at www.biomedcentral.com/submit

C) Biomed Central 